\title{
The Prediction of Clinical Outcome Using HbAlc in Acute Ischemic Stroke of the Deep Branch of Middle Cerebral Artery
}

\author{
Sung Bong Shin, $\mathrm{MD}^{1}$, Tae Uk Kim, MD, PhD ${ }^{1}$, Jung Keun Hyun, MD, PhD ${ }^{1,2,3}$, Jung Yoon Kim, MD, PhD ${ }^{1,4}$ \\ ${ }^{1}$ Department of Rehabilitation Medicine, Dankook University College of Medicine, Cheonan; ${ }^{2}$ Department of \\ Nanobiomedical Science \& WCU Research Center, Dankook University, Cheonan; ${ }^{3}$ Institute of Tissue Regeneration \\ Engineering (ITREN), Dankook University, Cheonan; ${ }^{4}$ Ewha Brain Institute, Ewha Womans University, Seoul, Korea
}

Objective To elucidate the association between glycemic control status and clinical outcomes in patients with acute ischemic stroke limited to the deep branch of the middle cerebral artery (MCA).

Methods We evaluated 65 subjects with first-ever ischemic stroke of the deep branches of the MCA, which was confirmed by magnetic resonance angiography. All subjects had blood hemoglobin Alc (HbAlc) measured at admission. They were classified into two groups according to the level of HbAlc (low $<7.0 \%$ or high $\geq 7.0 \%$ ). Neurological impairment and functional status were evaluated using the National Institutes of Health Stroke Scale (NIHSS), Functional Independence Measure (FIM), Korean version of Modified Barthel Index (K-MBI), Korean version of Mini-Mental State Examination (MMSE-K), and the Loewenstein Occupational Therapy Cognitive Assessment (LOTCA) at admission and discharge. Body mass index, serum glucose, homocysteine and cholesterol levels were also measured at admission.

Results The two groups did not show any difference in the NIHSS, FIM, K-MBI, MMSE-K, and LOTCA scores at any time point. Body mass index and levels of blood homocysteine and cholesterol were not different between the two groups. The serum blood glucose level at admission was negatively correlated with all outcome measures.

Conclusion We found that HbAlc cannot be used for predication of clinical outcome in patients with ischemic stroke of the deep branch of the middle cerebral artery.

Keywords Hemoglobin Alc, Stroke, Diabetes mellitus, Middle cerebral artery, Prognosis

Received Apr 22, 2015; Accepted Jul 7, 2015

Corresponding author: Jung Yoon Kim

Ewha Brain Institute, Ewha Womans University, 52, Ewhayeodae-gil, Seodaemun-gu, Seoul 03760, Korea

Tel: +82-2-3277-6559, Fax: +82-2-3277-6562, E-mail: schola21@gmail. com

(c) This is an open-access article distributed under the terms of the Creative Commons Attribution Non-Commercial License (http://creativecommons. org/licenses/by-nc/4.0) which permits unrestricted noncommercial use, distribution, and reproduction in any medium, provided the original work is properly cited.

Copyright $\odot 2015$ by Korean Academy of Rehabilitation Medicine

\section{INTRODUCTION}

Stroke is a condition that results in high mortality rates and severe disabilities. Most stroke survivors can and do experience improvements in their functional abilities, but the amount, rate, timing, pattern, type, and ultimate outcome of the improvements differ across patients and situations [1]. Numerous studies were conducted on the prognostic factors of acute ischemic stroke. Stroke severity and patient age are the main predictors of stroke 
outcome in the acute phase [2-6]. Additional important predictors include functional status prior to stroke, presence of comorbid medical conditions, etiologies and the vascular territories affected [7-10].

Diabetes mellitus is one of the established risk factors for stroke. It has been demonstrated that diabetic patients had worse residual neurological deficits and functional outcome when compared with nondiabetic patients [1113]. Hyperglycemia occurred in up to one-third of patients with acute ischemic stroke and was associated with higher mortalities independent of age and stroke severity $[14,15]$. However, few studies have assessed the effects of prestroke glycemic control status on clinical outcomes in acute stroke patients. In a study published in 2011, the association between prestroke glycemic control status and neurological or functional outcomes was evaluated in 3,627 patients with first-ever ischemic stroke. It was suggested that the serum hemoglobin Alc level on admission was a significant independent predictor for clinical outcomes [16]. However, clinical characteristics such as age, laboratory data, risk factors and stroke subtype were diverse in the previous study [16].

Hemoglobin Alc has a direct relationship with mean glycemia because erythrocytes are continuously glycated during their 120-day lifespan, which means that the rate of formation of glycated hemoglobin, also called HbAlc, is proportional to the ambient glucose concentration [17]. In the diabetes control and complication trial, an $\mathrm{HbAlc}$ of $6 \%$ corresponded to a mean serum glucose level of $135 \mathrm{mg} / \mathrm{dL}$, and the measurement of HbAlc has been the primary index of glycemia [17]. An HbAlc test can be used to diagnose pre-diabetes or diabetes and check the long-term control of blood glucose levels in people with diabetes. Serum blood glucose level changes during the day for many reasons, including medicine, diet, exercise, and the level of insulin in the blood, while the HbAlc test result is not affected by any recent changes [18]. HbAlc is independent risk factor for diabetic complication, with the risks of macrovascular events, such as cardiovascular death, non-fatal myocardial infarction or non-fatal stroke, and death only clearly lower when down at levels of $7 \%[19,20]$.

The middle cerebral artery (MCA) and its branches are the most commonly affected brain vessels in cerebral infarction. The MCA territory is involved in more than twothirds of all brain infarcts in a number of stroke registries.
Of MCA territory infarcts, $33 \%$ involve the deep MCA territory [21]. Diabetes influences the various vascular lesions in brain ischemia, and the predominant type of brain infarction is deep subcortical brain infarction [22]. In patients with ischemic stroke of the deep branch of the MCA, more than $75 \%$ of these patients have hypertension or diabetes [23].

The aim of this study was to elucidate the association between glycemic control status, defined by HbAlc on admission, and clinical outcomes in patients with acute ischemic stroke in the deep branch of MCA y territories. Vascular territories were confined to the deep branch of MCA territories in order to eliminate its effect on outcomes.

\section{MATERIALS AND METHODS}

\section{Subjects}

Sixty-five stroke patients who were admitted to Dankook University Hospital from May 2008 to December 2014 were enrolled. Inclusion criteria were diagnosis of first-ever ischemic stroke of the deep branch of the middle cerebral artery, the location of which was confirmed by diffusion weighted image and apparent diffusion coefficient of brain magnetic resonance imaging. Exclusion criteria were as follows: 1) insufficient communication skills, 2) unconsciousness, 3) aphasia, 4) visual loss, 5) hearing loss, 6) concurrent neurodegenerative diseases (e.g. Parkinson disease), or 7) prestroke impairment in daily living.

Serum HbAlc levels were measured at admission. Subjects were classified into two groups according to the level of HbAlc. The low HbAlc group consisted of subjects with $\mathrm{HbAlc}<7.0 \%$, and the high HbAlc group included subjects with $\mathrm{HbAlc} \geq 7.0 \%$. All subjects underwent conventional post stroke rehabilitation programs including exercise therapy and occupational therapy in 30-minute sessions, twice daily, according to their impairments and functions.

\section{Baseline characteristics}

Baseline characteristics included age, sex, comorbidities and stroke risk factors such as diabetes, hypertension, atrial fibrillation, hyperhomocysteinemia, hypercholesterolemia, body mass index, and smoking. Diabetes and hypertension were each defined according 
to previous diagnosis or current treatment with drugs. Microvascular complications of diabetes such as retinopathy and nephropathy were also evaluated. Retinopathy is the development of proliferative retinopathy, macular edema or diabetes-related blindness. Nephropathy is the development of microalbuminuria defined as a urinary albumin/creatinine ratio of more than $33.9 \mathrm{mg}$ or a doubling of the serum creatinine level to at least $200 \mu \mathrm{mol} /$ $\mathrm{L}$, with the need for renal-replacement therapy. Atrial fibrillation was evaluated through electrocardiography on admission or history of chronic atrial fibrillation. Serum glucose, cholesterol, homocysteine levels and body mass indices were measured on admission. Smoking was defined as history of smoking for more than 5 years.

\section{Outcome measurements}

Stroke severities were evaluated by using the National Institutes of Health Stroke Scale (NIHSS) score on admission. The NIHSS is a tool used to objectively quantify the impairment caused by a stroke, and is composed of 11 items: level of consciousness, horizontal eye movement, visual field test, facial palsy, motor arm, motor leg, limb ataxia, sensory, language, speech, extinction and inattention. Each of these specific abilities is given a score between 0 and 4 . For each item, a score of 0 typically indicates normal function in that specific ability, while a higher score is indicative of some level of impairment.
Functional status was measured using the Korean version of Modified Barthel Index (K-MBI) and Functional Independence Measure (FIM) at admission and discharge. The MBI is an ordinal scale used to measure performance in activities of daily living. It consists of 10 items: personal hygiene, bathing, eating, toileting, stair climbing, dressing, bowel control, bladder control, ambulation or wheelchair, and chair-bed transfer. The FIM measures the level of a patient's disability and indicates how much assistance is required for the individual to carry out activities of daily living. It has 18 items assessing 6 areas of function. These items fall into two domains, motor (13 items) and cognitive (5 items).

Cognitive functions were evaluated using the Korean version of Mini-Mental State Examination (MMSE-K) and Loewenstein Occupational Therapy Cognitive Assessment (LOTCA) at admission. The MMSE-K is a brief 30 point questionnaire test that is used to screen for cognitive impairment. It is composed of 8 categories: orientation to time, orientation to place, registration, attention and calculation, recall, language, repetition, and complex commands. LOTCA includes 25 subtests in 6 cognitive areas: orientation, visual and spatial perception, praxis, visuomotor organization, and thinking operations.

\section{Statistical analysis}

The baseline characteristics and outcome measure-

Table 1. Baseline characteristics of subjects

\begin{tabular}{|lccc}
\hline \multicolumn{1}{c}{ Characteristic } & Low HbAlc $(\mathbf{n = 4 4 )}$ & High HbAlc (n=21) & p-value \\
\hline Age $(\mathrm{yr})$ & $65.7 \pm 14.2$ & $65.6 \pm 12.6$ & 0.98 \\
\hline Female & $27(61)$ & $14(67)$ & 0.79 \\
\hline Diabetes & $6(14)$ & $16(76)$ & $<0.01^{* *}$ \\
\hline With complication & $5(11)$ & $6(29)$ & 0.15 \\
\hline Without complication & 1 & 10 & \\
Hypertension & $24(55)$ & $14(67)$ & 0.43 \\
\hline Atrial fibrillation & $4(9)$ & $2(10)$ & 0.96 \\
Smoking & $8(18)$ & $4(19)$ & 0.93 \\
\hline Body mass index $\left(\mathrm{kg} / \mathrm{m}^{2}\right)$ & $23.8 \pm 3.1$ & $25.1 \pm 3.8$ & 0.16 \\
\hline Serum homocysteine $(\mu \mathrm{mol} / \mathrm{L})$ & $11.7 \pm 5.0$ & $10.2 \pm 2.9$ & 0.22 \\
\hline Serum cholesterol $(\mathrm{mg} / \mathrm{dL})$ & $179.5 \pm 43.0$ & $191.4 \pm 46.2$ & 0.31 \\
\hline Serum glucose $(\mathrm{mg} / \mathrm{dL})$ & $139.4 \pm 34.3$ & $233.9 \pm 68.1$ & $<0.01^{* *}$ \\
\hline Length of stays $(\mathrm{day})$ & $38.1 \pm 23.0$ & $40.2 \pm 21.8$ & 0.73 \\
\hline
\end{tabular}

Values are presented as mean \pm standard deviation or number (\%).

HbAlc, hemoglobin Alc.

${ }^{* *} \mathrm{p}<0.01$. 
ments between the two groups were compared using the chi-square test or Fisher exact test and the independent t-test. The paired t-test was used to compare changes in K-MBI and FIM scores during hospitalization. The Pearson correlation analysis was performed to delineate the relationships between serum blood glucose and outcome measurements. Statistical significance level was set at 0.05 . Data are given as mean \pm standard deviation. Statistical analyses were performed using SPSS ver. 12.0 for Windows (SPSS Inc., Chicago, IL, USA).

\section{RESULTS}

\section{Baseline characteristics}

Of the 65 subjects, 24 were male and 41 female with age of $67.3 \pm 13.1$ years. The low HbAlc group consisted of 44 subjects (aged $65.7 \pm 14.2$ years), while the high HbAlc group consisted of 21 subjects (aged $65.6 \pm 12.6$ years). No statistically significant difference was found between the groups for age and gender.

The mean HbAlc levels were $5.8 \% \pm 0.5 \%$ in the low HbAlc group and $8.5 \% \pm 1.4 \%$ in the high HbAlc group.

Table 2. Changes in the NIHSS, K-MBI, FIM, MMSE-K, and LOTCA

\begin{tabular}{lcccc}
\hline \multicolumn{1}{c}{ Outcomes } & Low HbAlc $(\mathbf{n}=\mathbf{4 4})$ & High HbAlc $(\mathbf{n}=\mathbf{2 1})$ & $\left.\mathbf{p}_{\text {-value }}\right)^{\text {a) }}$ & p-value $^{\mathbf{b})}$ \\
\hline FIM & & & & \\
\hline Admission & $67.8 \pm 24.1$ & $64.3 \pm 22.1$ & 0.56 & $<0.01^{* *}$ \\
\hline Discharge & $86.0 \pm 27.4$ & $78.2 \pm 27.0$ & 0.29 & $<0.01^{* *}$ \\
K-MBI & & & & \\
Admission & $45.7 \pm 23.6$ & $42.2 \pm 19.3$ & 0.57 & $<0.01^{* *}$ \\
Discharge & $64.6 \pm 27.4$ & $57.4 \pm 24.0$ & 0.31 & $<0.01^{* *}$ \\
NIHSS & $5.6 \pm 4.3$ & $6.3 \pm 3.5$ & 0.48 & \\
MMSE-K & $19.7 \pm 8.0$ & $18.0 \pm 9.8$ & 0.45 & \\
LOTCA & $78.0 \pm 30.6$ & $76.4 \pm 29.7$ & 0.85 & \\
\hline
\end{tabular}

Values are presented as mean \pm standard deviation.

HbAlc, hemoglobin Alc; FIM, Functional Independence Measure; K-MBI, Korean version of Modified Barthel Index; NIHSS, National Institutes of Health Stroke Scale; MMSE, Mini-Mental State Examination; LOTCA, Loewenstein Occupational Therapy Cognitive Assessment.

${ }^{a}$ Between groups, ${ }^{\text {b) }}$ between admission and discharge.

${ }^{* *} \mathrm{p}<0.01$.

(A)

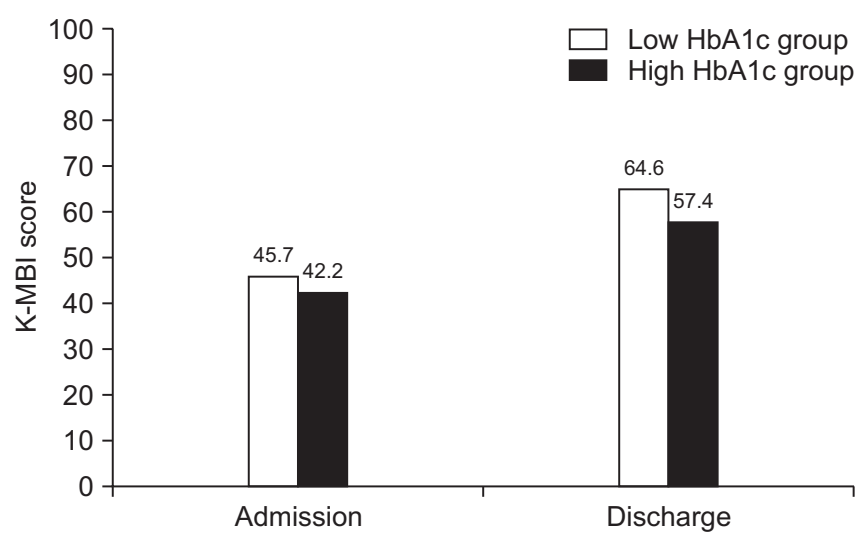

(B)

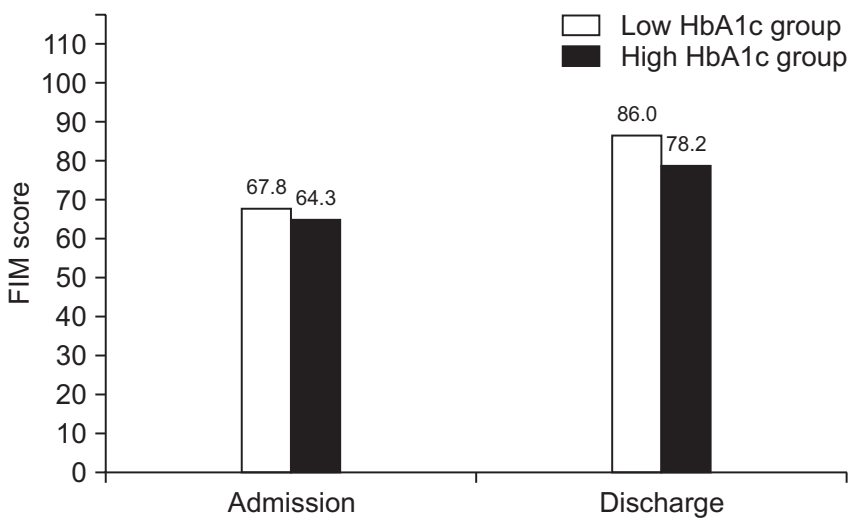

Fig. 1. (A) Korean version of Modified Barthel Index (K-MBI) at admission and discharge. Significant improvements were detected between admission and discharge in both groups $(\mathrm{p}<0.01)$. No differences were shown between groups. (B) Functional Independence Measure (FIM) at admission and discharge. Significant improvements were detected between admission and discharge in both groups $(\mathrm{p}<0.01)$. No differences were shown between groups. 
Table 3. Correlations between serum blood glucose and clinical outcomes

\begin{tabular}{lcl}
\hline \multicolumn{1}{c}{ Outcomes } & Coefficient & p-value \\
\hline FIM & & \\
Admission & -0.571 & $<0.01^{* *}$ \\
Discharge & -0.582 & $<0.01^{* *}$ \\
K-MBI & & \\
Admission & -0.570 & $<0.01^{* *}$ \\
Discharge & -0.554 & $<0.01^{* *}$ \\
NIHSS & 0.435 & $<0.01^{* *}$ \\
MMSE-K & -0.423 & $<0.01^{* *}$ \\
LOTCA & -0.405 & $<0.01^{* *}$ \\
\hline
\end{tabular}

Values are Pearson correlation coefficients.

HbAlc, hemoglobin Alc; FIM, Functional Independence Measure; K-MBI, Korean version of Modified Barthel Index; NIHSS, National Institutes of Health Stroke Scale; MMSE, Mini-Mental State Examination; LOTCA, Loewenstein Occupational Therapy Cognitive Assessment. ${ }^{* *} \mathrm{p}<0.01$.

Twenty-six subjects had diabetes and 11 subjects had diabetic complications. Diabetes was significantly higher in the high HbAlc group $(\mathrm{p}<0.01)$ but complications were not different between both groups. Thirty-eight patients had hypertension and six patients had atrial fibrillation. Other risk factors for stroke are shown in Table 1. Both groups did not have any difference in risk factors for stoke. The length of stays was $38.1 \pm 23.0$ days in the low HbAlc group, and $40.2 \pm 21.8$ days in the high HbAlc group.

\section{Outcome measures}

No statistically significant differences were found in the K-MBI, FIM, NIHSS, MMSE-K, and LOTCA scores between two groups (Table 2). Functional status confirmed by FIM and K-MBI was improved in all the subjects at discharge, but there were no differences between the groups in the degree of improvements (Fig. 1).

The serum blood glucose level was negatively correlated with the K-MBI, FIM, NIHSS, MMSE-K and LOTCA scores (Table 3). There were no differences according to the presence of diabetic complications in all clinical outcome measures (Table 4).

\section{DISCUSSION}

We investigated whether glycemic control status affects
Table 4. Clinical outcomes of subjects with or without microvascular complication of diabetes

\begin{tabular}{lccc}
\hline Outcomes & $\begin{array}{c}\text { Without } \\
\text { complication } \\
(\mathbf{n = 5 4 )}\end{array}$ & $\begin{array}{c}\text { With } \\
\text { complication } \\
(\mathbf{n}=\mathbf{1 1})\end{array}$ & p-value \\
\hline FIM & & & \\
\hline Admission & $67.8 \pm 23.0$ & $61.5 \pm 25.3$ & 0.42 \\
\hline Discharge & $84.8 \pm 27.2$ & $77.1 \pm 28.4$ & 0.40 \\
K-MBI & & & \\
\hline Admission & $45.7 \pm 22.8$ & $39.0 \pm 18.7$ & 0.37 \\
Discharge & $63.7 \pm 26.8$ & $55.4 \pm 24.0$ & 0.34 \\
NIHSS & $5.8 \pm 4.1$ & $6.0 \pm 3.7$ & 0.87 \\
MMSE-K & $19.5 \pm 8.2$ & $17.7 \pm 10.4$ & 0.54 \\
\hline LOTCA & $78.7 \pm 29.7$ & $71.5 \pm 32.8$ & 0.48 \\
\hline
\end{tabular}

Values are presented as mean \pm standard deviation. HbAlc, hemoglobin Alc; FIM, Functional Independence Measure; K-MBI, Korean version of Modified Barthel Index; NIHSS, National Institutes of Health Stroke Scale; MMSE, Mini-Mental State Examination; LOTCA, Loewenstein Occupational Therapy Cognitive Assessment.

the clinical outcome of acute ischemic stroke. The results of our study indicate that all the subjects showed significant functional recovery and similar clinical outcomes regardless of HbAlc levels, and a higher serum blood glucose level tended to be associated with poor clinical outcomes.

Several previous studies have found that neurological deterioration and a poor functional outcome were more common in patients with poor prestroke glycemic control. The level of HbAlc on admission was a predictor for poor survival and unfavorable functional outcomes $[16,24-26]$. In contrast, no statistically significant differences were found between the two groups in our study in terms of clinical outcome and functional recovery.

Several studies suggest that hyperglycemia after stroke had adverse effects on the clinical course of ischemic stroke, and was associated with the expansion of infarct volume as a result of neurotoxicity [26-29]. These results were also shown in the present study. However, in some studies, prestroke hyperglycemia was not associated with poststroke fasting blood glucose level [30,31]. A high proportion of stroke patients might have developed hyperglycemia even in the absence of preexisting diabetes since acute stroke itself is an acute stress condition $[32,33]$.

Other studies have demonstrated that blood glucose 
level after stroke was associated with stroke severity, but glycosylated hemoglobin (HbAlc) did not show any association with stroke severity $[34,35]$. This is consistent with our results. Therefore, clinical outcomes of ischemic stroke might be associated with poststroke hyperglycemia rather than prestroke glycemic control status (HbAlc on admission).

It should be noted that this study has several limitations. First, our study has low power attributable to the small sample size, and thus the results should be interpreted with caution. Second, neurological and cognitive improvements were not assessed on discharge, and only functional evaluations have been conducted in followup. Third, patients with insufficient communication skills, unconsciousness, aphasia, visual loss and hearing loss were excluded. We therefore do not know the effect of HbAlc in stroke patients with severe sensory deficits. Fourth, our sample was restricted to acute patients with ischemic stroke. Further studies are needed with larger samples of patients with severe deficits, and with longterm follow-ups.

In conclusion, it is suggested that HbAlc might not have any predictive value for clinical outcome in patients with ischemic stroke in the deep branch of the middle cerebral artery.

\section{CONFLICT OF INTEREST}

No potential conflict of interest relevant to this article was reported.

\section{REFERENCES}

1. Wolfe CD. The impact of stroke. Br Med Bull 2000;56: 275-86.

2. Adams HP Jr, Davis PH, Leira EC, Chang KC, Bendixen BH, Clarke WR, et al. Baseline NIH Stroke Scale score strongly predicts outcome after stroke: a report of the Trial of Org 10172 in Acute Stroke Treatment (TOAST). Neurology 1999;53:126-31.

3. Frankel MR, Morgenstern LB, Kwiatkowski T, Lu M, Tilley BC, Broderick JP, et al. Predicting prognosis after stroke: a placebo group analysis from the National Institute of Neurological Disorders and Stroke rt-PA Stroke Trial. Neurology 2000;55:952-9.

4. Muir KW, Weir CJ, Murray GD, Povey C, Lees KR. Com- parison of neurological scales and scoring systems for acute stroke prognosis. Stroke 1996;27:1817-20.

5. Andersen KK, Andersen ZJ, Olsen TS. Predictors of early and late case-fatality in a nationwide Danish study of 26,818 patients with first-ever ischemic stroke. Stroke 2011;42:2806-12.

6. Knoflach M, Matosevic B, Rucker M, Furtner M, Mair A, Wille G, et al. Functional recovery after ischemic stroke: a matter of age: data from the Austrian Stroke Unit Registry. Neurology 2012;78:279-85.

7. Petty GW, Brown RD Jr, Whisnant JP, Sicks JD, O'Fallon WM, Wiebers DO. Ischemic stroke subtypes : a population-based study of functional outcome, survival, and recurrence. Stroke 2000;31:1062-8.

8. Nedeltchev K, der Maur TA, Georgiadis D, Arnold M, Caso V, Mattle HP, et al. Ischaemic stroke in young adults: predictors of outcome and recurrence. J Neurol Neurosurg Psychiatry 2005;76:191-5.

9. Sumer MM, Ozdemir I, Tascilar N. Predictors of outcome after acute ischemic stroke. Acta Neurol Scand 2003;107:276-80.

10. Saposnik G, Raptis S, Kapral MK, Liu Y, Tu JV, Mamdani $\mathrm{M}$, et al. The iScore predicts poor functional outcomes early after hospitalization for an acute ischemic stroke. Stroke 2011;42:3421-8.

11. Shindo A, Tomimoto H. Diabetes and ischemic stroke. Brain Nerve 2014;66:107-19.

12. Cantu-Brito C, Mimenza-Alvarado A, Sanchez-Hernandez JJ. Diabetes mellitus and aging as a risk factor for cerebral vascular disease: epidemiology, pathophysiology and prevention. Rev Invest Clin 2010; 62:333-42.

13. Mankovsky BN, Ziegler D. Stroke in patients with diabetes mellitus. Diabetes Metab Res Rev 2004;20:26887.

14. Luitse MJ, Biessels GJ, Rutten GE, Kappelle LJ. Diabetes, hyperglycaemia, and acute ischaemic stroke. Lancet Neurol 2012;11:261-71.

15. Kruyt ND, Biessels GJ, Devries JH, Roos YB. Hyperglycemia in acute ischemic stroke: pathophysiology and clinical management. Nat Rev Neurol 2010;6:145-55.

16. Kamouchi M, Matsuki T, Hata J, Kuwashiro T, Ago T, Sambongi Y, et al. Prestroke glycemic control is associated with the functional outcome in acute ischemic stroke: the Fukuoka Stroke Registry. Stroke 2011; 42:2788-94. 
17. Saudek CD, Derr RL, Kalyani RR. Assessing glycemia in diabetes using self-monitoring blood glucose and hemoglobin Alc. JAMA 2006;295:1688-97.

18. American Diabetes Association. Standards of medical care in diabetes, 2014. Diabetes Care 2014;37 Suppl 1:S14-80.

19. Rohlfing CL, Wiedmeyer HM, Little RR, England JD, Tennill A, Goldstein DE. Defining the relationship between plasma glucose and $\mathrm{HbA}(1 \mathrm{c})$ : analysis of glucose profiles and $\mathrm{HbA}(1 \mathrm{c})$ in the Diabetes Control and Complications Trial. Diabetes Care 2002;25:275-8.

20. Zoungas S, Chalmers J, Ninomiya T, Li Q, Cooper ME, Colagiuri S, et al. Association of HbAlc levels with vascular complications and death in patients with type 2 diabetes: evidence of glycaemic thresholds. Diabetologia 2012;55:636-43.

21. Caplan LR, Van Gijn J. Stroke syndromes. 3rd ed. New York: Cambridge University press; 2012. p. 344-58.

22. Caplan LR. Diabetes and brain ischemia. Diabetes 1996;45 Suppl 3:S95-7.

23. Ghika J, Bogousslavsky J, Regli F. Infarcts in the territory of lenticulostriate branches from the middle cerebral artery. Etiological factors and clinical features in 65 cases. Schweiz Arch Neurol Psychiatr 1991;142:5-18.

24. Hjalmarsson C, Manhem K, Bokemark L, Andersson B. The role of prestrike glycemic control on severity and outcome of acute ischemic stroke. Stroke Res Treat 2014;2014:694569.

25. Wu S, Wang C, Jia Q, Liu G, Hoff K, Wang X, et al. $\mathrm{HbAlc}$ is associated with increased all-cause mortality in the first year after acute ischemic stroke. Neurol Res 2014;36:444-52.

26. Lei C, Wu B, Liu M, Chen Y. Association between hemoglobin $A_{1} C$ levels and clinical outcome in ischemic stroke patients with or without diabetes. J Clin Neurosci 2015;22:498-503.
27. Baird TA, Parsons MW, Phan T, Butcher KS, Desmond PM, Tress BM, et al. Persistent poststroke hyperglycemia is independently associated with infarct expansion and worse clinical outcome. Stroke 2003;34:220814.

28. Garg R, Chaudhuri A, Munschauer F, Dandona P. Hyperglycemia, insulin, and acute ischemic stroke: a mechanistic justification for a trial of insulin infusion therapy. Stroke 2006;37:267-73.

29. Williams LS, Rotich J, Qi R, Fineberg N, Espay A, Bruno A, et al. Effects of admission hyperglycemia on mortality and costs in acute ischemic stroke. Neurology 2002;59:67-71.

30. Weil ZM. Ischemia-induced hyperglycemia: consequences, neuroendocrine regulation, and a role for RAGE. Horm Behav 2012;62:280-5.

31. Chmielewska B, Hasiec T, Belniak-Legiec E. Value of glucose, glycosylated hemoglobin and fructosamine in blood of patients with ischemic cerebral infarction without diabetes during the early stage of the disease. Ann Univ Mariae Curie Sklodowska Med 1996;51:61-8.

32. Allport LE, Butcher KS, Baird TA, MacGregor L, Desmond PM, Tress BM, et al. Insular cortical ischemia is independently associated with acute stress hyperglycemia. Stroke 2004;35:1886-91.

33. Capes SE, Hunt D, Malmberg K, Pathak P, Gerstein HC. Stress hyperglycemia and prognosis of stroke in nondiabetic and diabetic patients: a systematic overview. Stroke 2001;32:2426-32.

34. Ogbera AO, Oshinaike OO, Dada O, Brodie-Mends A, Ekpebegh C. Glucose and lipid assessment in patients with acute stroke. Int Arch Med 2014;7:45.

35. Murros K, Fogelholm R, Kettunen S, Vuorela AL, Valve J. Blood glucose, glycosylated haemoglobin, and outcome of ischemic brain infarction. J Neurol Sci 1992;111:59-64. 